\title{
SOME PROPERTIES OF THE RESOLVENT OF STURM-LIOUVILLE OPERATORS ON UNBOUNDED TIME SCALES
}

\author{
BILENDER P. ALLAHVERDIEV and HÜSEYIN TUNA
}

\begin{abstract}
In this article, we investigate the resolvent operator of Sturm-Liouville problem on unbounded time scales. We obtain integral representations for the resolvent of this operator. Later, we discuss some properties of the resolvent operator, such as Hilbert-Schmidt's kernel property and compactness. Finally, we give a formula for the Titchmarsh-Weyl function of the Sturm-Liouville problem on unbounded time scales.
\end{abstract}

MSC 2010. 34N05, 34L05, 47A10.

Key words. Hilbert-Schmidth kernel, resolvent operator, singular point, spectral function, Sturm-Liouville operator, time scale, Titchmarsh-Weyl function.

\section{REFERENCES}

[1] R.P. Agarwal, M. Bohner and J.P.Y. Wong, Sturm-Liouville eigenvalue problems on time scales, Appl. Math. Comput., 99 (1999), 153-166.

[2] R.P. Agarwal, M. Bohner and W.T. Li, Nonoscillation and Oscillation Theory for Functional Differential Equations, Monographs and Textbooks in Pure and Applied Mathematics, Vol. 267, Marcel Dekker, New York, 2004.

[3] B.P. Allahverdiev and H. Tuna, Spectral analysis of singular Sturm-Liouville operators on time scales, Ann. Univ. Mariae Curie-Skłodowska Sect. A, 72 (2018), 1-11.

[4] B.P. Allahverdiev and H. Tuna, Resolvent operator of singular Dirac system with transmission conditions, Rad Hrvat. Akad. Znan. Umjet. Mat. Znan, to appear.

[5] D.R. Anderson, G.Sh. Guseinov and J. Hoffacker, Higher-order self-adjoint boundaryvalue problems on time scales, J. Comput. Appl. Math., 194 (2006), 309-342.

[6] D.R. Anderson and J.P.Y. Wong, Positive solutions for second-order semipositone problems on time scales, Comput. Math. Appl., 58 (2009), 281-291.

[7] F.M. Atici and G.Sh. Guseinov, On Green's functions and positive solutions for boundary value problems on time scales, J. Comput. Appl. Math., 141 (2002), 75-99.

[8] M. Bohner and A. Peterson, Dynamic Equations on Time Scales, Birkhäuser, Boston, 2001.

[9] M. Bohner and A. Peterson, Advances in Dynamic Equations on Time Scales, Birkhäuser, Boston, 2003.

[10] F.A. Davidson and B.P. Rynne, Eigenfunction expansions in $L^{2}$ spaces for boundary value problems on time-scales, J. Math. Anal. Appl., 335 (2007), 1038-1051.

The authors thank the referee for his helpful comments and suggestions.

DOI: $10.24193 /$ mathcluj.2019.1.01 
[11] G.Sh. Guseinov, Self-adjoint boundary value problems on time scales and symmetric Green's functions, Turkish J. Math., 29 (2005), 365-380.

[12] G.Sh. Guseinov, An expansion theorem for a Sturm-Liouville operator on semiunbounded time scales, Adv. Dyn. Syst. Appl., 3 (2008), 147-160.

[13] S. Hilger, Analysis on measure chains-a unified approach to continuous and discrete calculus, Results Math., 18 (1990), 18-56.

[14] J. Hoffacker, Green's functions and eigenvalue comparisons for a focal problem on time scales, Comput. Math. Appl., 45 (2003), 1339-1368

[15] A. Huseynov, Eigenfunction expansion associated with the one-dimensional Schrödinger equation on semi-infinite time scale intervals, Rep. Math. Phys., 66 (2010), 207-235.

[16] A. Huseynov, Existence of a spectral measure for second-order delta dynamic equations on semi-infinite time scale intervals, Chaos Solitons Fractals, 44 (2011), 769-777.

[17] A. Huseynov, Weyl's limit point and limit circle for a dynamic systems. Dynamical Systems and Methods, Springer, New York, 2012, 215-225.

[18] M.A. Jones, B. Song and D.M. Thomas, Controlling wound healing through debridement, Mathematical and Computer Modelling, 40 (2004), 1057-1064.

[19] K. Knopp, Elements of the Theory of Functions, Dover, New York, 1952.

[20] A.N. Kolmogorov and S.V. Fomin, Introductory Real Analysis. Translated by R.A. Silverman, Dover Publications, New York, 1970.

[21] V. Lakshmikantham, S. Sivasundaram and B. Kaymakcalan, Dynamic Systems on Measure Chains, Kluwer Academic Publishers, Dordrecht, 1996.

[22] B.M. Levitan and I.S. Sargsjan, Sturm-Liouville and Dirac Operators. Mathematics and its Applications (Soviet Series), Kluwer Academic Publishers Group, Dordrecht, 1991.

[23] M.A. Naimark, Linear Differential Operators, New York, 1968; 2nd Ed. (in Russian), Nauka, Moscow, 1969.

[24] B.P. Rynne, $L^{2}$ spaces and boundary value problems on time-scales, J. Math. Anal. Appl., 328 (2007), 1217-1236.

[25] V. Spedding, Taming nature's numbers, New Scientist, 179 (2003), 28-31.

[26] D.M. Thomas, L. Vandemuelebroeke and K. Yamaguchi, A mathematical evolution model for phytoremediation of metals, Discrete Contin. Dyn. Syst. Ser. B, 5 (2005), 411-422.

[27] E. C. Titchmarsh, Eigenfunction Expansions Associated with Second-Order Differential Equations. Part I, 2nd Ed., Clarendon Press, Oxford, 1962.

[28] H. Tuna, Completeness of the rootvectors of a dissipative Sturm-Liouville operators on time scales, Appl. Math. Comput., 228 (2014), 108-115.

[29] C. Zhang and Y. Shi, Eigenvalues of second-order symmetric equations on time scales with periodic and antiperiodic boundary conditions, Appl. Math. Comput., 203 (2008), 284-296.

Received May 14, 2018

Accepted December 17, 2018
Süleyman Demirel University

Department of Mathematics 32260 Isparta, Turkey

E-mail: bilenderpasaoglu@sdu.edu.tr

\author{
Mehmet Akif Ersoy University \\ Department of Mathematics \\ 15030 Burdur, Turkey \\ E-mail: hustuna@gmail.com
}

